\title{
Thermodynamic and structural studies of cation-macrocycle interaction
}

\author{
C.-Y. Zhu, R. M. Izatt", T.-M. Wang, P. Huszthy, and J. S. Bradshaw \\ Department of Chemistry, Brigham Young University, Provo, UT 84602-1022, U.S.A.
}

\begin{abstract}
The rapid progress in host-guest chemistry involving macrocycles has been due in no small part to the availability of reliable and extensive thermodynamic data for a large number of host-guest systems. Although valuable information can be derived from $\Delta H$ and $\Delta S$ values, few calorimetric data have been reported for host-guest systems. The procedures required to obtain reliable thermodynamic data are discussed and some of the kinds of information which these data can provide are given together with an example. Recent studies have demonstrated the power of combined thermodynamic and spectroscopic data in understanding host-guest interactions. Examples of these studies are presented.
\end{abstract}

\section{INTRODUCTION}

Thermodynamic data are available for a large number of interactions involving macrocycles with cations (refs. 1,2), anions (ref. 2), and neutral molecules (ref. 3). These data have been important aids in guiding the design of new macrocycles, and in the development of novel applications for macrocycles. The effectiveness of thermodynamic data in providing this service is dependent on the data being accurate. A perusal of recent compilations (refs. 1-3) shows that in many cases log $K$ values for specific host-guest interactions determined in different laboratories may differ significantly. It is desirable to develop standards by having different laboratories determine $\log K$ and/or $\Delta H$ values for the same system. Agreement among laboratories would provide systems which could be used to check on the experimental procedures for subsequent investigators. Such systems are available in the case of non-macrocyclic systems (ref. 4). Use of papers on critical data evaluation (ref. 5) provides access to other systems. The $\mathrm{Na}^{+}-18$-crown- 6 system in methanol has been studied repeatedly using different methods. The $\log \mathrm{K}$ values for this interaction are in good agreement (refs. 1,2) making it a possible candidate for consideration as a standard system.

Few $\Delta H$ and $\Delta S$ data are available for macrocycle-guest interactions although such data offer great promise for gaining increased insight into these interactions. The common practice of calculating $\Delta H$ from the variation of $\log K$ with temperature can result in inaccurate values. In a recent calorimetric-NMR study of macrocycle-protonated amine interaction (ref. 6 ) we demonstrated that (1) $\log K$ values determined by the two methods agreed well with larger standard deviations in the NMR procedure, and (2) the NMR method resulted in $\Delta H$ values which differed by more than ten $\mathrm{kj} /$ mole from those determined by calorimetry. Interpretations based on the NMR $\Delta H$ values could be erroneous.

In this manuscript, discussions together with examples are presented to emphasize the usefulness of thermodynamic data, the necessity of obtaining accurate data, and the power of combining thermodynamic data with $X$-ray and NMR results to provide structural information about macrocycle-guest complexes. The use of thermodynamic data to quantitate enantiomeric recognition and suggested future work is also presented.

\section{STRUCTURAL INFORMATION FROM THERMODYNAMIC AND SPECTROSCOPIC DATA}

A better understanding of the chemistry of host-guest interactions requires a good knowledge about the structural features of the host-guest complexes in addition to the knowledge of complexation strengths. Structural information can be obtained in a number of ways. For solving crystalline state structures, $\mathrm{X}$-ray crystallography is the standard technique. For learning structural features in gaseous phases, electron diffraction spectroscopy (ref. 7 ) and IR may be informative for simple systems. Since most reactions occur in solution, the structural features in solution are of particular interest. Modern NMR spectroscopy (ref. 8) has proven to be extremely powerful in obtaining structural features in solution for a broad range of compounds. Other spectroscopic techniques such as IR, UV/VIS, ESR, etc. (ref. 9) may also provide valuable structural 
information for selected systems. Thermodynamic values also offer structural information in addition to providing accurate quantitation for host-guest interactions. Examples of extracting structural information from thermodynamic values, especially from $\Delta H$ and $\Delta S$, will be given below. Because of the power of NMR spectroscopy in elucidating solution structures, the combination of thermodynamic data and NMR results are useful in understanding the chemistry of host-guest interactions. Examples of the use of NMR spectra to provide important structural information in our macrocycle-guest systems are also given in the following pharagraphs.

\section{Information provided by Log $K, \Delta H$, and $\Delta S$ values}

Thermodynamic values ( $\log K, \Delta H$, and $\Delta S$ ) provide accurate quantitation of chemical interactions from a macroscopic point of view. However, thermodynamic values, especially $\Delta H$ and $\Delta S$, can also offer some structural information and a microscopic view of the processes under study. In the following example, the importance of $\Delta H$ and $\Delta S$ values in providing structural information is demonstrated using a non-macrocyclic system.

Rizzarelli and his coworkers have been interested in the field of metal ion assisted molecular recognition and they have found (ref. 10) that $D$-histidine anion ( $D$-HisO-) forms a more stable ternary complex than $L$-histidine anion ( $L$-His $\mathrm{H}^{-}$) with $\mathrm{Cu}^{2+}$ and $L$-phenylalanine anion ( $\left.L-\mathrm{PheO}^{-}\right)$in aqueous solution. This enantiomeric recognition disappears when the $L$-PheO $\mathrm{O}^{*}$ is replaced by $L-A^{\prime a O}{ }^{-}$(alanine anion) in the formation of the ternary complexes. Table 1 lists the $\log K, \Delta H$, and $\Delta S$ values for the formation of the ternary complexes of interest. Table 1 also lists the thermodynamic values for two related systems.

Table 1. $\log K, \Delta H$, and $\Delta S$ values for the formation of

$\mathrm{Cu}^{2+}$ complexes in aqueous solution and at $25^{\circ} \mathrm{C}$ (ref. 10)

\begin{tabular}{cccc}
\hline Complex & $\log K$ & $\Delta H\left(\mathrm{kj} \cdot \mathrm{mol}^{-1}\right)$ & $\Delta S\left(j \cdot \mathrm{mol}^{-1} \cdot \mathrm{K}^{-1}\right)$ \\
\hline$(D) \mathrm{HisO}^{-}-\mathrm{Cu}^{2+}-(L) \mathrm{PheO}^{-}$ & $17.70(1)$ & $-66.7(2)$ & $115.1(5)$ \\
$(L) \mathrm{HiSO}^{-}-\mathrm{Cu}^{2+}-(L) \mathrm{PheO}^{-}$ & $17.53(1)$ & $-65.1(2)$ & $117.2(5)$ \\
$\mathrm{Cu}^{2+}-\mathrm{PheO}^{-}$ & 7.77 & -23.0 & 71.1 \\
$\mathrm{HiSO}^{-}-\mathrm{Cu}^{2+}$ & 10.15 & -44.4 & 45.6 \\
\hline
\end{tabular}

In order to understand the origin of enantiomeric recognition in the His $\mathrm{O}^{-}-L-\mathrm{PheO}^{-} \cdot \mathrm{Cu}^{2+}$ ternary system, it is necessary to know whether or not the two ternary complexes containing $D$ - and $L$-HisO $0^{-}$are much different structurally. It is seen from Table 1 that the $\Delta H$ values for the two ternary complexes differ by $1.6 \mathrm{kj} \cdot$ mol $^{-1}$, which is much smaller than the value for the formation of a Cu${ }^{2+}-\mathrm{N}$ coordination bond (approximately $23 \mathrm{kj} \cdot \mathrm{mol}^{-1}$, ref 10 ), while the $\Delta S$ values for the two ternary complexes differ by $2.1 \mathrm{j} \cdot \mathrm{mol}^{-1} \cdot \mathrm{K}^{-1}$, which is again much smaller than the value for the formation of a $\mathrm{COO}^{*} \cdot \mathrm{Cu}^{2+}$ coordination bond (approximately $32 \mathrm{j} \cdot \mathrm{mol}^{-1} \cdot \mathrm{K}^{-1}$,ref. 10). Also, the $\Delta H$ and $\Delta S$ values for either one of the ternary complexes are approximately equal to the sum of those for the $\mathrm{Cu}^{2+}$-HisO- and $\mathrm{Cu}^{2+}-\mathrm{PheO}^{-}$binary complexes, respectively. This suggests that both ternary complexes involve the same number and type of coordination bonds. In each of the two His $O^{-}-L$. $\mathrm{PheO}^{-}-\mathrm{Cu}^{2+}$ complexes, two nitrogen and one oxygen donor atoms from $\mathrm{His}^{-}$and one nitrogen and one oxygen donor atoms from $\mathrm{PheO}^{-}$are involved in the coordination of $\mathrm{Cu}^{2+}$. Therefore, the two HisO- $L-\mathrm{PheO}^{-}-\mathrm{Cu}^{2+}$ ternary complexes are similar in complex geometry. The only possible difference between the two complexes is that in one complex there is a $\pi-\pi$ stacking between the phenyl group and the imidazole group, while in the other one no such $\pi-\pi$ stacking exists. The difference of $1.6 \mathrm{kj} \cdot \mathrm{mol}^{-1}$ in $\Delta H$ may very well be the contribution of the $\pi-\pi$ interaction. The reason why enantiomeric recognition disappears in $\mathrm{HiSO}^{-}-\mathrm{L}-\mathrm{AlaO}^{-}-\mathrm{Cu}^{2+}$ system is that the alanine anion does not bave a phenyl group to overlap with the imidazole group.

In this example, we see the ability of $\Delta H$ and $\Delta S$ values to provide structural information. However, in order to be able to extract structural information from $\Delta H$ and $\Delta S$ values, one must bear in mind that first, the thermodynamic values must be of high accuracy, and second, the interpretation of $\Delta H$ and $\Delta S$ values for a new system must be made with reference to those values of the parent or similar systems. An isolated interpretation of $\Delta H$ and $\Delta S$ values could be misleading.

\section{Selection of $\mathrm{Ag}^{+}$over $\mathrm{Hg}^{2+}$ by a macrocyclic ligand}

Selective complexation of transition metal ions by macrocyclic ligands may be achieved by changing the number, type, and location of the donor groups in the macrocyclic ring. However, the selectivity of $\mathrm{Ag}^{+}$over $\mathrm{Hg}^{2+}$ by macrocyclic ligands has rarely been achieved because of the greater affinity of $\mathrm{Hg}^{2+}$ over $\mathrm{Ag}^{+}$for most 'soft', 'borderline', and even 'hard' donor atoms and groups and the similar ionic radii of the two ions. In this example, we demonstrate that the different coordination geometries of $\mathrm{Ag}^{+}$and $\mathrm{Hg}^{2+}$ together with their relative affinities for various donor atoms or groups can be used to generate a reversal of the normal $\mathrm{Hg}^{2+}$ over $\mathrm{Ag}^{+}$selectivity order using the macrocycle, pyridonothio-18-crown-6 (PT18C6) (ref. 11). In this case, the reversal in selectivity was confirmed by $\log K$ measurements. The cause for this reversal in selectivity was interpreted in terms of the differences in coordination geometries and the relative donor affinities of $\mathrm{Hg}^{2+}$ and $\mathrm{Ag}^{+}$. The interpretation was based on the structural information about the two complexes as obtained from ${ }^{13} \mathrm{C} N M R$ results. 


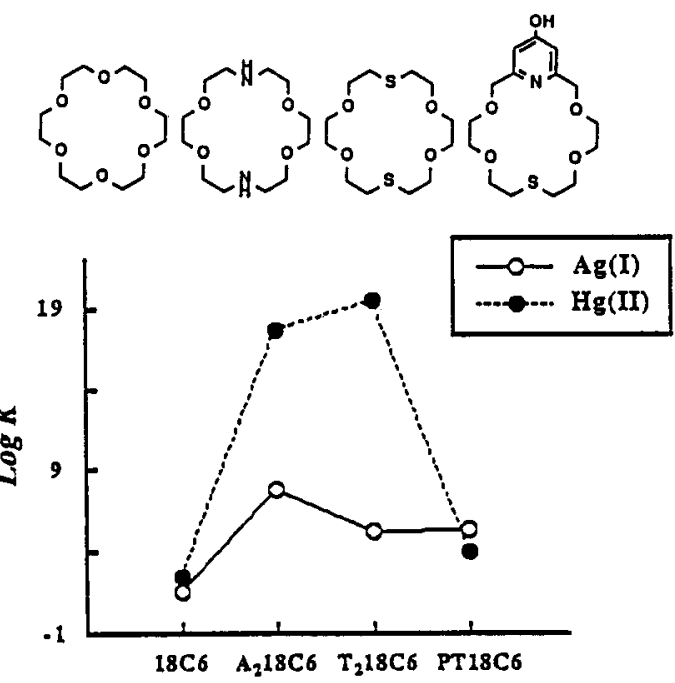

Fig.1 Plot of $\log K$ vs macrocycle type for $\mathrm{Ag}^{+}$and $\mathrm{Hg}^{2+}$ complexes.

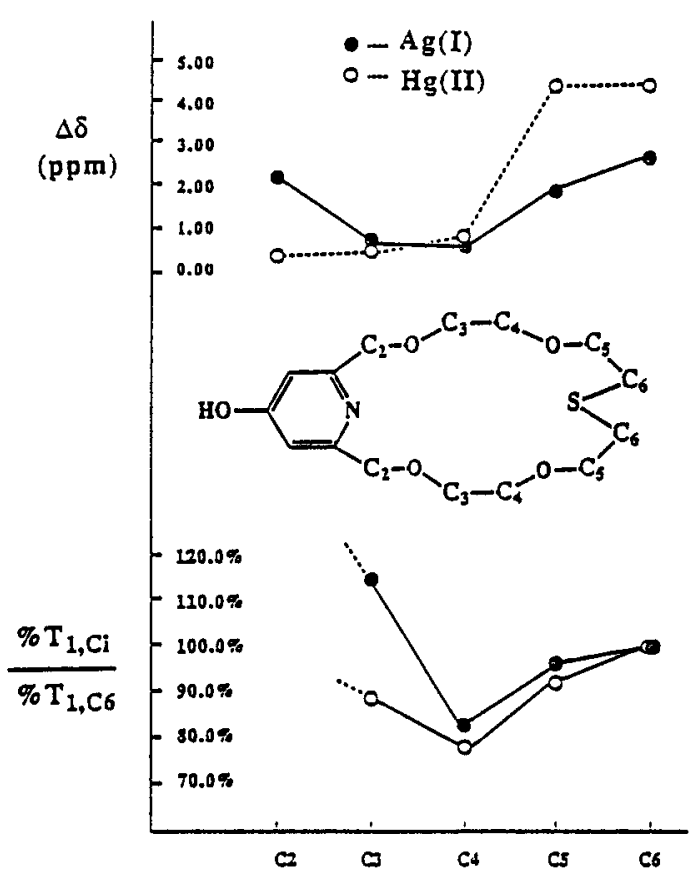

Fig.2 Chemical Shift and relative $\mathrm{T}_{1}$ changes for PT18C6 carbons $\left(C_{i}\right)$ upon complexation

Log $K$ values for the interactions of $\mathrm{Ag}^{+}$and $\mathrm{Hg}^{2+}$ with the macrocyclic ligands studied are plotted against the macrocycle type in Figure 1. A reversal of the common order of selectivity of $\mathrm{Hg}^{2+}$ over $\mathrm{Ag}^{+}$can be seen for ligand PT18C6. This reversal suggests that the introduction of a pyridone group enhances the affinity of the ligand for $\mathrm{Ag}^{+}$. Since PT18C6 has two non-oxygen donor atoms, it is interesting to see if both of these donor atoms are involved in binding the metal ion. In order to answer the question concerning the binding sites, the ${ }^{13} \mathrm{C}$ NMR technique was employed. It was found that upon formation of complexes with the metal ions, both the chemical shift and the $T_{1}$ relaxation time for the carbon atoms next to the nitrogen and sulfur donor atoms underwent significant change. The extent of this change depends on the interaction strength between the donor atom and the metal ion. Figure 2 shows the chemical shift changes and the $T_{1}$ changes for different carbon atoms in PT18C6 upon formation of complexes with $\mathrm{Ag}^{+}$and $\mathrm{Hg}^{2+}$. The $\Delta \delta$ values resulting from complexation indicate that $\mathrm{Hg}^{2+}$ lacks affinity for the pyridone binding subunit. However, $\mathrm{Ag}^{+}$binds strongly with the pyridone group, as illustrated by the large shift (2.1 $\mathrm{ppm}$ ) of C-2. The downfield shift of C-2 in the $\mathrm{Ag}^{+}$-PT18C6 complex indicates a lowered electron density in C-2 as a result of electron donation by the pyridone moiety through the pyridone nitrogen to $\mathrm{Ag}^{+}$. The large anisotropic shifts of $\mathrm{C}-6$ in $\mathrm{Ag}^{+}-\mathrm{PT} 18 \mathrm{C} 6$ and $\mathrm{Hg}^{2+}-\mathrm{PT} 18 \mathrm{C} 6$ are consistent with the expectation of large affinities of the thiaether group with both $\mathrm{Hg}^{2+}$ and $\mathrm{Ag}^{+}$. As we proceed from $\mathrm{C}-5$ to $\mathrm{C}-2$, the absolute isotropic carbon shifts decrease in both complexes from $\mathrm{C}-5$ to $\mathrm{C}-4$. However, the absolute shift for the $\mathrm{Ag}^{+}-\mathrm{PT} 18 \mathrm{C} 6$ complex increases from C-3 to $\mathrm{C}-2$ indicating strong interaction of $\mathrm{Ag}^{+}$with the pyridone portion of the ligand. Therefore, $\mathrm{Ag}^{+}$ appears to bind covalently to both sulfur and pyridone nitrogen. This linear coordination brings the $\mathrm{Ag}^{+}$into the macrocycle cavity making cation-dipole interaction with the ether oxygen atoms possible. On the other hand, $\mathrm{Hg}^{2+}$ binds tightly with only the thiaether fragment, leaving the pyridone portion of the ligand free to move about.

The ${ }^{13} \mathrm{C}$ relaxation times further support the structural analysis described above. It is well known that $T_{1}$ values for any given molecule depend upon molecular mobility (tumbling) as determined by the internal degrees of freedom of the molecule. The measurement of $T_{1}$ values for each resolvable resonance can lead to estimates of relative mobilities of the different portions of the macrocyclic ring framework in solution. Metal ion complexation results in an increase in the effective molecular weight. Thus, there is less freedom for the complex to tumble resulting in an increase in correlation time, or a decrease in $T_{1}$. When PT18C6 is bound by either $\mathrm{Hg}^{2+}$ or $\mathrm{Ag}^{+}$, a dramatic decrease in the mobility of all carbons is observed. The relaxation time of $\mathrm{C}-6$ is reduced to a large degree in both the $\mathrm{Hg}^{2+}$ and $\mathrm{Ag}^{+}$complexes, which is consistent with the thiophilicity of $\mathrm{Hg}^{2+}$ and $\mathrm{Ag}^{+}$ions. As we proceed from $\mathrm{C}-6$ to $\mathrm{C}-3$, the ratio of the percentage decrease of $\mathrm{T}_{1}$ for a given carbon ( $\mathrm{Ci}$ ) relative to that for $\mathrm{C}-6$ becomes smaller in the case of $\mathrm{Hg}^{2+}-\mathrm{PT} 18 \mathrm{C} 6$ with a small increase between $\mathrm{C}-4$ and $\mathrm{C}-3$ In the case of $\mathrm{Ag}^{+}$, the ratio also decreases from $\mathrm{C}-6$ to $\mathrm{C}-4$, but increases significantly between $\mathrm{C}-4$ and $\mathrm{C}-3$, indicating a tighter binding of $\mathrm{Ag}^{+}$ with the pyridone portion of the ligand. 
In this example, we see that the microscopic information of $T_{1}$ and $\delta$ provides a solid basis for the explanation of the macroscopic selectivity of PT18C6 for $\mathrm{Ag}^{+}$over $\mathrm{Hg}^{2+}$.

\section{Evidence for a $\pi \cdot \pi$ interaction from ${ }^{1} \mathrm{H}$ NMR data}

Chiral diketopyridino-18-crown-6 ligand (Fig. 3) has been found to show excellent enantiomeric recognition toward chiral

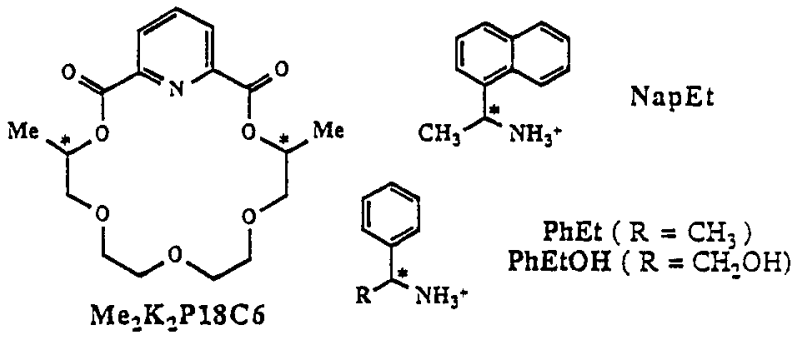

Fig.3 Diketopyridino-18-crown-6 and three primary ammonium cations.

naphthyl- and phenylethylammonium salts (ref. 12). It has long been suspected that the $\pi-\pi$ interaction between the pyridine ring of the ligand and the $\alpha$-aromatic group (either naphthyl or phenyl) of the ammonium salt played an important role in causing enantiomeric recognition (ref. 13). The $\pi-\pi$ interaction can serve as the second restricting force in addition to threepoint hydrogen bonding to hold the ammonium cation from free rotation on top of the ligand molecule. Since chiral diketopyridino-18-crown-6 exhibits excellent enantiomeric recognition in several organic solvents toward both naphthyl- and phenylethylammonium cations, it is logical to expect that both the naphthyl and the phenyl groups of the ammonium cations can overlap and have $\pi-\pi$ interaction with the pyridine ring of the ligand in their complexes. However, it was found in an NMR study using polar organic solvents that $\pi-\pi$ interaction happens between the naphthyl group and the pyridine ring, but not between the phenyl group and the pyridine ring (ref. 13 and Fig. 4).

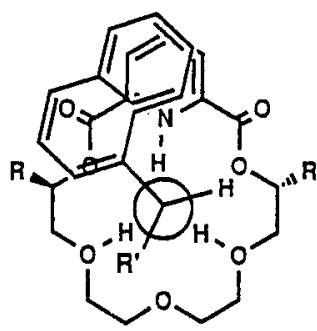

in Solution

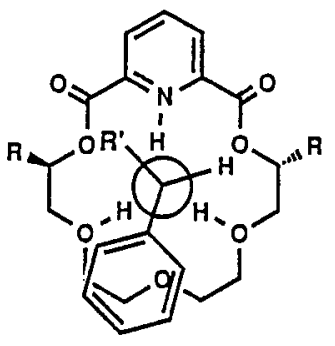

in Solution

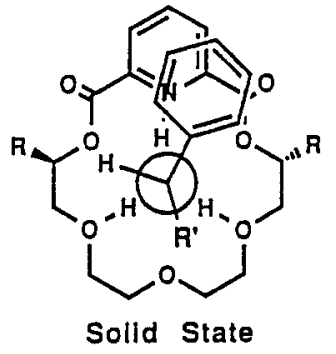

Solld State

Fig.4 Illustration of the complex structures in solution and in the crystalline state.

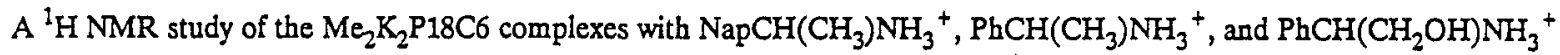
(ref. 13) showed that in the formation of the complex with $\mathrm{NapCH}\left(\mathrm{CH}_{3}\right) \mathrm{NH}_{3}{ }^{+}$, the pyridine proton signals of the ligand underwent a large upfield shift (up to $0.15 \mathrm{ppm}$ ), while in the formation of each complex with $\mathrm{PbCH}\left(\mathrm{CH}_{3}\right) \mathrm{NH}_{3}{ }^{+}$and $\mathrm{PhCH}\left(\mathrm{CH}_{2} \mathrm{OH}\right) \mathrm{NH}_{3}{ }^{+}$, the pyridine proton signals of the ligand underwent a significant downfield shift (up to $0.15 \mathrm{ppm}$ ). The upfield shift of the pyridine proton signals in the first instance indicates the overlap between the naphthyl group of $\mathrm{NapCH}\left(\mathrm{CH}_{3}\right) \mathrm{NH}_{3}{ }^{+}$and the pyridine ring of $\mathrm{Me}_{2} \mathrm{~K}_{2} \mathrm{P} 18 \mathrm{C} 6$. The downfield shift of the pyridine proton signals in the latter two instances, however, indicates that the phenyl group of either $\mathrm{PhCH}\left(\mathrm{CH}_{3}\right) \mathrm{NH}_{3}{ }^{+}$or $\mathrm{PhCH}\left(\mathrm{CH}_{2} \mathrm{OH}\right) \mathrm{NH}_{3}{ }^{+}$is away from and does not overlap with the pyridine ring of the ligand. Evidence for the separation of the phenyl group from the pyridine ring in the $\mathrm{Me}_{2} \mathrm{~K}_{2} \mathrm{P} 18 \mathrm{C} 6$ complex with $\mathrm{PhCH}\left(\mathrm{CH}_{2} \mathrm{OH}\right) \mathrm{NH}_{3}{ }^{+}$is also found in the ${ }^{1} \mathrm{H}$ NMR NOESY spectrum of the complex in $50 \% \mathrm{CD}_{3} \mathrm{OD}-50 \% \mathrm{CDCl}_{3}$ (ref. 13). In the NOESY spectrum, off-diagonal signais correlating the chemical shifts of the pyridine protons and those of the phenyl protons are absent. Instead, off-diagonal signals are present which correlate the pyridine chemical shifts of the ligand and the methylene chemical shift of $\mathrm{PhCH}\left(\mathrm{CH}_{2} \mathrm{OH}\right) \mathrm{NH}_{3}{ }^{+}$, indicating that the methylene protons of the ammonium cation are in close proximity $(<5 \AA)$ to the pyridine protons of the ligand. The phenyl group of the ammonium cation, then, must be positioned far away from the pyridine ring of the ligand.

In contrast to the observed solution structure of the $\mathrm{Me}_{2} \mathrm{~K}_{2} \mathrm{P} 18 \mathrm{C} 6$ complex with $\mathrm{PhCH}\left(\mathrm{CH}_{2} \mathrm{OH}\right) \mathrm{NH}_{3}{ }^{+}$in $50 \% \mathrm{CD}_{3} \mathrm{OD}$. $50 \% \mathrm{CDCl}_{3}$, the phenyl group of the ammonium cation is found to be partly overlapping with, rather than being positioned away from, the pyridine ring of the ligand in the crystal structure of the same complex (ref. 13 and Fig. 4). This set of systems 
provides a good example of the marked difference which is possible between the crystal structure of a complex and the corresponding solution structure. The data also suggest that the cause for the absence of the $\pi-\pi$ overlap in the solution structures is solvent related, rather than resulting from an unfavorable conformational strain.

One explanation for the facts stated above is the following. In the presence of the solvent, the keto oxygens in each $\mathrm{Me}_{2} \mathrm{~K}_{2} \mathrm{P} 18 \mathrm{C} 6$ molecule are solvated and the $\pi-\pi$ overlap is possible only at the cost of removing the solvent molecules from the keto oxygens in each $\mathrm{Me}_{2} \mathrm{~K}_{2} \mathrm{P} 18 \mathrm{C} 6$ complex with $\mathrm{NapCH}\left(\mathrm{CH}_{3}\right) \mathrm{NH}_{3}{ }^{+}, \mathrm{PhCH}\left(\mathrm{CH}_{3}\right) \mathrm{NH}_{3}{ }^{+}$, and $\mathrm{PhCH}\left(\mathrm{CH}{ }_{2} \mathrm{OH}\right) \mathrm{NH}_{3}{ }^{+}$. Since the phenyl group has fewer $\pi$ electrons and is smaller than the naphthyl group, the $\pi-\pi$ interaction between the phenyl group of the ammonium cation and the pyridine ring of $\mathrm{Me}_{2} \mathrm{~K}_{2} \mathrm{P} 18 \mathrm{C} 6$ is not energetic enough to overcome the cost to remove the solvent molecules from the keto oxygens of the ligand. Hence, the $\pi-\pi$ overlap between the phenyl group of the ammonium cation and the pyridine ring of the ligand is not observed in solution. On the other hand, the $\pi-\pi$ interaction of the naphthyl group with the pyridine ring is sufficiently energetic to allow $\pi-\pi$ overlap in the solution. Therefore, in the complexes of $\mathrm{Me}_{2} \mathrm{~K}_{2} \mathrm{P} 18 \mathrm{C} 6$ with $\mathrm{PhCH}\left(\mathrm{CH}_{3}\right) \mathrm{NH}_{3}{ }^{+}$and $\mathrm{PhCH}\left(\mathrm{CH}_{2} \mathrm{OH}\right) \mathrm{NH}_{3}{ }^{+}$the desolvation energy, instead of $\pi-\pi$ interaction, serves as the second restricting force that holds the ammonium cation in place and plays an important role in realizing enantiomeric recognition in these two systems.

\section{Evidence for involvement of the side arms of a lariat ether ligand in cation complexation}

A dipeptidediaza-18-crown-6 ligand, $\mathrm{A}_{2} 18 \mathrm{C} 6$ (gly-leu-OMe) ${ }_{2}$ (Fig. 5), has been found to bind $\mathrm{Ca}^{2+}$ very well in aqueous

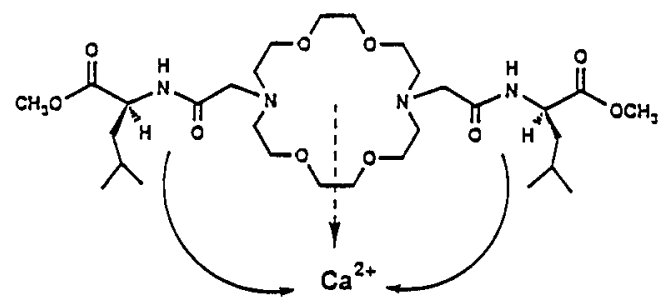

Fig.5 Illustration of $\mathrm{A}_{2} 18 \mathrm{C} 6$ (gly-leu-OMe) $)_{2}$ in forming complex with $\mathrm{Ca}^{2+}$.

solution (ref. 14). The $\log K$ and $\Delta H$ values for the formation of the complex were found to be 7.8 and $-41.4 \mathrm{kj} \mathrm{mol}^{-1}$, respectively. Compared to simple diaza-18-crown-6 (log $K=2.4$, ref. 2), $\mathrm{A}_{2} 18 \mathrm{C} 6$ (gly-leulOMe) ${ }_{2}$ is a much better ligand for complexing $\mathrm{Ca}^{2+}$ in aqueous solution. Therefore, it is likely that the two side arms of $\mathrm{A}_{2} 18 \mathrm{C} 6$ (gly-leu-OMe) ${ }_{2}$ are involved in the complexation of $\mathrm{Ca}^{2+}$ and contribute positively to the complex stability. In order to confirm the involvement of the side arms, ${ }^{1}$ H NMR spectra of the free and complexed ligand were obtained (ref. 14). By comparing the NMR spectrum of the complexed ligand with that of the free ligand, one can see the significant chemical shift changes for the protons in the side arms, as well as for the protons in the macrocyclic ring. These chemical shift changes provide evidence for the involvement of the side arms in complexation. As to which donor atoms are involved in the binding of $\mathrm{Ca}^{2+}, \mathrm{more} \mathrm{NMR}$ work, especially the measurement of ${ }^{13} \mathrm{C}$ chemical shifts and relaxation times, needs to be done.

\section{QUANTITATION OF ENANTIOMERIC RECOGNITION IN CHIRAL CROWN ETHER- AMMONIUM SALT SYSTEMS}

Macrocycles offer unusual opportunities for the study of molecular recognition. Chiral macrocyclic ligands have also proven to be promising in enantiomeric recognition (refs. 15,16). We have designed and synthesized a series of chiral macrocyclic ligands (refs. 17-19). Some of these ligands have been found to exhibit excellent enantiomeric recognition toward chiral primary ammoniuum salts (refs. 17-19). Systematic studies on these chiral ligands have been conducted in our laboratory in the hope of understanding the origin of enantiomeric recognition.

Understanding enantiomeric recognition requires that the interactions involved be quantitated. This quantification provides the basis for evaluating guest selectivity and binding strength. Correlation of the quantified properties of host-guest complexes with their molecular structures should provide the basis for understanding host-guest recognition as well as for predicting the ligands which should be synthesized in order to obtain desired selectivities. Others have used various quantities to quantify enantiomeric recognition. One of these quantities is the chromatographic separation factor $\alpha$ which is determined when a macrcocycle-containing column is used in the separation of two enantiomers (ref. 20). Other quantities include differences in membrane transport (ref. 21), in extractability (ref. 22), in activation energy of complex dissociation ( $\Delta G^{\ddagger}$ ) (refs. 18,23), and in complex stability $(\log K$ ) (ref. 17-19). Among these quantities, however, only the complex stability (log $K)$ can be used directly to describe the ability of the chiral ligand to recognize guest enantiomers. Other quantities (except $\Delta G^{*}$ ) describe more than one interaction or process, and they are sometimes called 'apparent' quantities. Unless the correlations between these 'apparent' quantities and those for their constituent interactions have been well established, conclusions concerning the causes of chiral recognition cannot be made from such data. Therefore, we have chosen the 
difference in complex stabilities $(\Delta \log K)$ as the unique measure for the enantiomeric recognition displayed in our systems. Since $\Delta \log K$ directly expresses the ability of a chiral ligand to exhibit enantiomeric recognition, comparison of $\Delta \log K$ values and correlation of $\Delta \log K$ values with the structural and conditional parameters of the chiral systems are considered valid.

Figure 6 shows some of the chiral macrocyclic ligands we have studied and Table 2 lists the $\log K$ and $\Delta \log K$ values for the interaction of these chiral ligands with enantiomers of some chiral primary ammonium salts. It is seen from Table 2 that<smiles>OCCOCCOCc1cccc(COCC(=P)COCCP)n1</smiles>

$\mathrm{R}=\mathrm{Me}(1), \mathrm{Ph}(2), \mathrm{tBu}(3)$
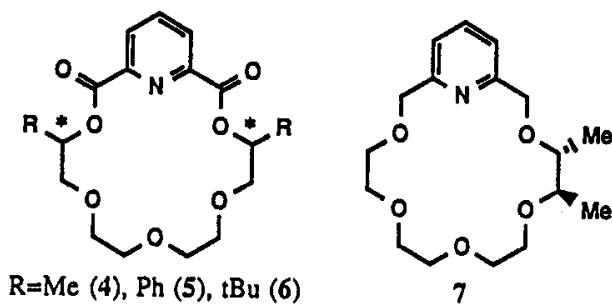

7

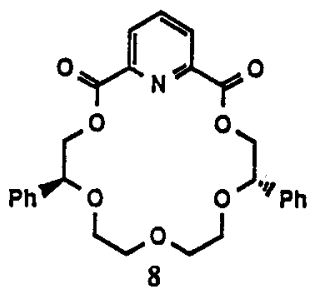

Fig.6 Chiral macrocyclic ligands studied

Table 2. $\log K, \Delta H$, and $\Delta S$ values ${ }^{\mathrm{a}}$ for the interactions of the macrocyclic ligands with enantiomers of several primary ammonium cations at $25^{\circ} \mathrm{C}$

\begin{tabular}{|c|c|c|c|c|c|c|c|}
\hline Ligand & Cation $^{\mathrm{b}}$ & Solvt. $^{\mathrm{c}}$ & Meth. ${ }^{d}$ & $\log K$ & $\Delta H^{e}$ & $\Delta S^{e}$ & $\Delta \log K^{f}$ \\
\hline \multirow[t]{6}{*}{$(S S)-1$} & $(R)$-NapEt & $\mathbf{M}$ & Cal. & $3.00(2)$ & $-29.1(1)$ & -40.3 & \\
\hline & (S)-NapEt & $\mathbf{M}$ & Cal. & $2.76(2)$ & $-22.3(1)$ & -21.8 & $0.24(4)$ \\
\hline & (R)-PhEt & $1 \mathrm{M} / 1 \mathrm{C}$ & NMR & $3.62(5)$ & & & \\
\hline & (S)-PhEt & $1 \mathrm{M} / 1 \mathrm{C}$ & NMR & $3.29(5)$ & & & $0.33(10)$ \\
\hline & (R)-PhEtOH & $1 \mathrm{M} / 1 \mathrm{C}$ & NMR & $3.21(5)$ & & & \\
\hline & $(S)$-PhEtOH & $1 \mathrm{M} / 1 \mathrm{C}$ & NMR & $3.27(5)$ & & & $-0.06(10)$ \\
\hline \multirow[t]{4}{*}{$(R R)-2$} & (R)-NapEt & $\mathbf{M}$ & NMR & $2.92(5)$ & & & \\
\hline & $(S)$-NapEt & $\mathbf{M}$ & NMR & $3.10(5)$ & & & $0.18(10)$ \\
\hline & (R)-PhEt & $\mathbf{M}$ & NMR & $2.91(5)$ & & & \\
\hline & (S)-PhEt & $\mathbf{M}$ & NMR & $3.10(5)$ & & & $0.19(10)$ \\
\hline \multirow[t]{2}{*}{$(S S)-3$} & $(R)$-NapEt & $1 \mathrm{M} / 9 \mathrm{C}$ & NMR & $1.33(5)$ & & & \\
\hline & (S)-NapEt & $1 \mathrm{M} / 9 \mathrm{C}$ & NMR & $0.62(8)$ & & & $0.71(13)$ \\
\hline \multirow{4}{*}{$(S S)-4$} & (R)-NapEt & $\mathbf{M}$ & Cal. & $2.47(2)$ & $-27.6(1)$ & -10.8 & \\
\hline & (S)-NapEt & M & Cal. & $2.06(2)$ & $-26.4(1)$ & -11.8 & $0.41(4)$ \\
\hline & $(R)-\mathrm{PhEt}$ & $\mathbf{M}$ & NMR & $2.33(5)$ & & & \\
\hline & $(S)$-PhEt & $\mathbf{M}$ & NMR & $1.88(5)$ & & & $0.45(10)$ \\
\hline \multirow[t]{6}{*}{$(S S)-5$} & (R)-NapEt & $7 \mathrm{M} / 3 \mathrm{C}$ & NMR & $2.15(6)$ & & & \\
\hline & (S)-NapEt & $7 \mathrm{M} / 3 \mathrm{C}$ & NMR & $<1.30$ & & & $>0.85$ \\
\hline & $(S)-\mathrm{PhEt}$ & $1 \mathrm{M} / 1 \mathrm{C}$ & NMR & $2.62(5)$ & & & \\
\hline & $(R)-\mathrm{PhEt}$ & $1 \mathrm{M} / 1 \mathrm{C}$ & NMR & $2.06(5)$ & & & $0.56(10)$ \\
\hline & (R)-PhEtOH & $1 \mathrm{M} / 1 \mathrm{C}$ & NMR & $2.24(5)$ & & & \\
\hline & $(S)$-PhEtOH & $1 \mathrm{M} / 1 \mathrm{C}$ & NMR & $2.95(6)$ & & & $-0.71(11)$ \\
\hline \multirow[t]{2}{*}{$(S S)-6$} & $(R)$-NapEt & $1 \mathrm{M} / 9 \mathrm{C}$ & NMR & $N / R$ & & & \\
\hline & (S)-NapEt & $1 \mathrm{M} / 9 \mathrm{C}$ & NMR & $\mathrm{N} / \mathrm{R}$ & & & \\
\hline \multirow[t]{2}{*}{$(R R)-7$} & (R)-NapEt & M & NMR & $3.00(5)$ & & & \\
\hline & $(S)$-NapEt & $\mathbf{M}$ & NMR & $2.94(4)$ & & & $-0.06(9)$ \\
\hline \multirow[t]{4}{*}{$(S S)-8$} & (R)-NapEt & $1 \mathrm{M} / 1 \mathrm{C}$ & Cal. & $2.57(3)$ & & & \\
\hline & (S)-NapEt & $1 \mathrm{M} / 1 \mathrm{C}$ & Cal. & $2.35(3)$ & & & $0.22(6)$ \\
\hline & (R)-PhEt & $\mathbf{M}$ & Cal. & $2.58(3)$ & $-17.3(2)$ & -8.6 & \\
\hline & $(S)$-PhEt & $\mathbf{M}$ & Cal. & $2.44(3)$ & $-17.7(2)$ & -12.8 & $0.14(6)$ \\
\hline
\end{tabular}

${ }^{a}$ Uncertainties are indicated in the parentheses following each value. N/R indicates that the value can not be determined due to lack of significant heat or chemical shift change. ${ }^{b}$ Perchlorate salts were used for all of the ammonium cations listed in this table. The notations for the ammonium cations are defined in Figure 3. ${ }^{\mathrm{c}} \mathrm{M}=$ methanol, $\mathrm{C}=$ chloroform, $1 \mathrm{M} / 1 \mathrm{C}=50 \%$ methanol-50\% chloroform ( $\mathrm{v} / \mathrm{v})$. For NMR experiments, $100 \%$ deuterated solvents were used. For calorimetry, non-deuterated solvents were used. ${ }^{\mathrm{d}} \mathrm{NMR}={ }^{1} \mathrm{H}$ NMR method (ref. 6), Cal. = titration calorimetry. ${ }^{\mathrm{e}}$ Units for $\Delta H$ and $\Delta S$ values are $\mathrm{kj} \cdot \mathrm{mol}^{-1}$ and $\mathrm{j} \cdot \mathrm{mol}^{-1} \cdot \mathrm{K}^{-1}$, respectively. ${ }^{\mathrm{f}} \Delta \log K=\log K(S S-R)$ $\log K(S S-S)$ or $\log K(R R-S)-\log K(R R-R)$. 
chiral ligand 1 shows reasonably good enantiomeric recognition toward chiral naphthyl- and phenylethylammonium cations. Ligands 2 and 3 differ from 1 in that the two methyl substituents in 1 are replaced by two phenyl groups in 2 and two tertbutyl groups in 3, respectively. Although the size increase from methyl to phenyl does not bring improvement in enantiomeric recognition, the size increase from methyl to tert-butyl improves the extent of enantiomeric recognition significantly. However, the complex stabilities drop sharply as a result of the substitution of methyl groups by tert-butyl groups. Although the $\Delta \log K$ value for 1-NapEt system is not directly comparable to that for the 3-NapEt system because the solvents are different, the $\Delta \log K$ increase from 0.24 to 0.71 can still be partly attributed to the effect of substituent size increase because the effect of solvent on enantiomeric recognition is not significant enough to cause this much $\Delta \log K$ increase (ref. 24).

Ligand 4 differs from 1 by having two keto oxygens next to the pyridine ring. Compared to 1 , ligand 4 displayed improved enantiomeric recognition toward NapEt and PhEt. This improvement may be attributed to the increased rigidity of ligand 4. Replacing the methyl substituents in $\mathbf{4}$ by phenyl groups leads to significant improvement in enantiomeric recognition by 5 and a slight drop in complex stabilities. Ligand 6 is expected to show even greater improvement in recognition. However, the complex stabilities drop so much that no interaction can be detected.

Ligand 7 differs from 1 in that the two chiral centers are located on the same side of the pyridine ring. As expected, ligand 7 displays no enantiomeric recognition toward NapEt. This is probably because the bulky group of NapEt can avoid steric repulsion by locating on the other side of the pyridine ring where no methyl substituents are present. Ligand $\mathbf{8}$ differs from 5 by having two chiral centers one position farther away from the pyridine ring. The recognition displayed by 8 is found to be much smaller than that by 5 . It is evident that the position of chiral centers in the ligand molecule plays a key role in causing enantiomeric recognition.

\section{SUGGESTED FUTURE WORK}

The number of determinations of $\log K$ values for macrocycle-guest interactions has increased markedly over the past decade (refs. 1-3). It is desirable to have more $\Delta H$ and $\Delta S$ values for these interactions. It is prefered that these values be obtained by calorimetric measurement. A second need is for more standard systems which can be used by an investigator to check experimental and calculation procedures. It would be helpful if several investigators carried out such studies in a planned way leading to the availability of standard systems both for $K$ and $\Delta H$ measurements. Most available standard systems are valid in aqueous solution. It would be desirable to have these for non-aqueous systems where mutiple reactions may occur (ref. 6) and where solvent itself may present experimental problems. A third need is for more systematic studies of solvent and temperature effects on macrocycle-guest interactions. A notable example of such a study involving solvents is that of Smithrud and Diederich (ref. 25). Such studies could provide a wealth of information concerning solute-solvent interactions. Especially useful would be the resulting $\Delta H, \Delta S$, and $\Delta C_{\mathrm{p}}$ values resulting from such studies. Finally, it is desirable to have more combined thermodynamic-spectroscopic-molecular modeling studies. The examples presented here show some of the possibilities of such investigations.

\section{Acknowledgement}

Appreciation is expressed to the Office of Naval Research (chiral crown ether-protonated ammonium ion interaction) and the Department of Energy Office of Basic Energy Sciences, Contract No. DE-FG02-86ER13463 (macrocycle-metal ion interaction) for support of this work.

\section{REFERENCES}

1. R. M. Izatt, J. S. Bradshaw, S. A. Nielson, J. D. Lamb, J. J. Christensen and D. Sen, Chem. Rev., 85, 271 (1985).

2. R. M. Izatt, K. Pawlak, J. S. Bradshaw, and R. L. Bruening, Chem. Rev., 91, 1721 (1991).

3. R. M. Izatt, K. Pawlak, J. S. Bradshaw, and R. L. Bruening, and B. J. Tarbet, Chem. Rev., 92, 1261 (1992).

4. L. D. Pettit, Pure and Appl. Chem., 56, 247 (1984).

5. R. M. Smith and A. E. Martell, Critical Stability Constants, 6 vols., Plenum Press, New York $(1977,1982,1989)$.

6. C. Y. Zhu, J. S. Bradshaw, J. L. Oscarson, and R. M. Izatt, J. Incl. Phenom., 12, 275 (1992).

7. I. Hargittai in Sterochemical Applications of Gas-Phase Electron Diffraction, I. Hargittai and M. Hargittai eds., pp 1-54, VCH Publishers, Inc., New York (1988).

8. J. K. M. Sanders and B. K. Hunter, Modem NMR Spectroscopy, Oxford University Press, Oxford (1987).

9. R. V. Parish, NMR, NQR, EPR, and Mössbauer Spectroscopy in Inorganic Chemistry, Ellis Horwood Limited, London (1990).

10. G. Borghesani, F. Pulidori, M. Remelli, R. Purrello, and E. Rizzarelli, J. Chem. Soc., Dalton Trans., 2095 (1990).

11. G. Wu, W. Jiang, J. D. Lamb, J. S. Bradshaw, and R. M. Izatt, J. Am. Chem. Soc., 113, 6538 (1991).

12. J. S. Bradshaw, P. Huszthy, C. W. McDaniel, M. Oue, C. Y. Zhu, R. M. Izatt, and S. Lifson, J. Coord. Chem. Section $B$. , in press.

13. R. M. Izatt, C. Y. Zhu, N. K. Dalley, J. C. Curtis, X. Kou, and J. S. Bradshaw, J. Phys. Org. Chem., in press. 
14. C. Y. Zhu, K. Arnold, M. Tsesarakaja, J. E. Trafton, R. M. Izatt, and G. W. Gokel, in preparation.

15. E. P. Kyba, M. G. Siegel, L. R. Sousa, G. D. Y. Sogah, and D. J. Cram, J. Am. Chem. Soc., 95, 2691 (1973).

16. R. B. Davidson, J. S. Bradshaw, B. A. Jones, N. K. Dalley, J. J. Christensen, R. M. Izatt, F. G. Morin, and D. M. Grant, J. Org. Chem., 49, 353 (1984).

17. J. S. Bradshaw, P. Huszthy, C. W. McDaniel, C. Y. Zhu, N. K. Dalley, R. M. Izatt, and S. Lifson, J. Org. Chem., 55, 3129 (1990).

18. P. Huszthy, J. S. Bradshaw, C. Y. Zhu, R. M. Izatt, and S. Lifson, J. Org. Chem., 56, 3330 (1991).

19. P. Huszthy, M. Oue, J. S. Bradshaw, C. Y. Zhu, T. Wang, N. K. Dalley, J. C. Curtis, and R. M. Izatt, J. Org. Chem., in press.

20. W. H. Pirkle, G. S. Mahler, T. C. Pochapsky, M. H. Hynn, J. Chromatogr., 388, 307 (1987).

21. G. D. Y. Sogah and D. J. Cram, J. Chem. Soc., Chem. Commun., 1259 (1975).

22. G. W. Gokel, J. M. Timko, and D. J. Cram, J. Chem. Soc., Chem. Commun., 444 (1975).

23. D. J. Chadwick, I. A. Cliffe, and I. O. Sutherland, J. Chem. Soc., Chem. Commun., 992 (1981),

24. R. M. Izatt, C. Y. Zhu, T. Wang, P. Huszthy, J. Hathaway, X. Zhang, J. C. Curtis, and J. S. Bradshaw, in preparation.

25. D. B. Smithrud and F. D. Diederich, J. Am. Chem. Soc., 112, 339 (1990). 